\title{
PERFIL SANGUÍNEO DE LA VICUÑA (VICUGNA VICUGNA) EN CONDICIONES DE CAUTIVERIO EN HUANCAVELICA, PERÚ
}

\author{
BLOOD PROFILE OF VICUÑA (VICUGNA VICUGNA) IN CAPTIVITY \\ AT HUANCAVELICA, PERU
}

\author{
Sánchez Araujo, V. ${ }^{1 *}$, Chavez Araujo, E. ${ }^{1}$, Paucar Chanca, R. ${ }^{1}$, López Villar, J. ${ }^{1}$ \\ y Cordova Romero, J. ${ }^{1}$ \\ ${ }^{1}$ Universidad Nacional de Huancavelica. Ciudad Universitaria de Paturpampa s/n. Huancavelica-Perú.
} *vgsa18@hotmail.com

\section{Palabras ClaVe adicionales}

Vicuñas. Proteína total. Colesterol. Glucosa. Espectrofotómetro.

\section{RESUMEN}

Con el objetivo de determinar el perfil bioquímico sérico de la vicuña en condiciones de cautiverio (alimentadas con pastos cultivados), se obtuvieron los niveles de proteína total, glucosa y colesterol, respectivamente, en 16 muestras de sangre de vicuñas juveniles machos (cautiverio) en el establo de la Universidad Nacional de Huancavelica (UNH). Los análisis se realizaron en el Laboratorio de Fisiología Animal y Bioquímica de la UNH, mediante espectrofotometría de luz visible (Génesis 10 UV), según el protocolo establecido por Wiener (2000). Los resultados obtenidos de glucosa, colesterol y proteínas totales fueron: $100,06 \pm 36,4 ; 21,69 \pm 6,5$ y $9,19 \pm 1,8$ respectivamente. Estos resultados difieren con los reportados por Siguas (2005), Fowler (1998), Garnica et al. (2003), en condiciones normales (alimentados con pastos silvestres) donde se encuentran diferencias significativas respecto a la proteína total siendo mayor en condiciones de cautiverio (alimentados con pastos cultivados), lo que obedece al cambio en el tipo de alimento que consumen en ambas condiciones estos camélidos.

\section{SUMMARY}

In order to determine the serum biochemical profile of the vicuna in conditions of captivity (fed cultivated grasses), were obtained protein levels, glucose and cholesterol. Sixteen samples of blood male vicuña youth (captive) in the barn at the National University of Huancavelica (UNH) were

Recibido: 30-10-08. Aceptado: 16-12-08.

\section{AdDitionAl KEYWORDS}

Vicunas. Total protein. Cholesterol. Glucose. Spectrophotometer.

collected. The analysis were performed at the Laboratory of Animal Physiology and Biochemistry of the UNH, through visible light spectrophotometry (UV Genesis 10), according to the protocol established by Wiener (2000). The results of glucose, cholesterol and total protein were: 100.06 $\pm 36.4,21.69 \pm 9.19 \pm 1.8$ and 6.5 respectively. These results differ with those reported by Siguas (2005), Fowler (1998), Garnica et al. (2003) who, under normal conditions (fed with wild grasses), found significant differences in terms of total protein that was higher in conditions of captivity (fed cultivated grasses), which reflects the change in the food consumed in these conditions by both camelid types.

\section{INTRODUCCIÓN}

Las vicuñas (Vicugna vicugna), son camélidos sudamericanos que son manejados en áreas marginales entre 3000 y 4600 msnm, cuyas condiciones climáticas y de producción de forraje son adversas para otras especies (Lichtenstein et al., 2002). La principal población de este camélido, se encuentra en el Perú, siendo un recurso valioso para el poblador altoandino gracias a su fina fibra que tiene alto valor económico. En razón que los perfiles metabólicos vienen siendo usados en el ganado vacuno para ayudar en el diagnóstico de problemas 


\section{SÁNCHEZ ARAUJO ETAL.}

metabólicos y enfermedades (Campos et al., 2005). El conocimiento de los niveles de glucosa, bilirrubina, triglicéridos, colesterol, transaminasas (GOT y GPT), proteínas totales entre otros, permitirían conocer manifestaciones clínicas de ciertas enfermedades (Garnica et al., 2003) y poder así tomar las medidas correctivas sanitarias.

\section{MATERIAL YMÉTODOS}

Se obtuvieron 16 muestras de sangre de vicuñas juveniles machos (cautiverio) en el establo de la Universidad Nacional de Huancavelica (UNH), las muestras fueron tomadas por punción de la vena yugular, usando tubos Vacutainer ${ }^{\circledR}$. Los análisis se realizaron en el Laboratorio de Fisiología Animal y Bioquímica de la UNH, mediante espectrofotometría de luz visible (Génesis $10 \mathrm{UV})$, según el protocolo establecido por Wiener (2000). Se estableció el rango, media y desviación estándar de cada parámetro evaluado, usando SPSS versión 12.

\section{RESULTADOSYDISCUSIÓN}

En base a los resultados reportados en la tabla I, encontramos que los niveles de proteína total son semejantes a los reportados en equinos, bovinos y cerdos (Kraft, 1998), pero son elevados con lo reportado para vicuñas en ambiente natural (Garnica et al., 2003) e igualmente para alpacas y llamas (Oevermann et al., 2004). Asimismo respecto a los niveles de glucosa, son superiores a los valores señalados en equino, bovino, cerdo, gato y perro (Kraft, 1998); siendo superiores a lo indicado por Garnica et al. (2003) en vicuñas y ligeramente supe-

\section{BIBLIOGRAFÍA}

Campos, R., Gonzáles, F., Lacerda, L. y Coldebella, A. 2005. Perfil metabólico obtenido de pool de sueros o muestras individuales. Arch. Zootec., 54: 113-116.

Cebra, C.K., Tornquist, S.J., Van Saun, R.J. and Smith, B.B. 2001. Glucose tolerance testing in
Tabla I. Valores de glucosa, colesterol y proteinas totales. (Values of glucose, cholesterol and total protein).

\begin{tabular}{lccc}
\hline Variable* & \multicolumn{2}{c}{ Rango } & Promedio \pm DS \\
& Mínimo & Máximo & \\
\hline Proteína total & 5,82 & 11,78 & $9,19 \pm 1,8$ \\
Glucosa & 50,89 & 178,90 & $100,06 \pm 36,4$ \\
Colesterol & 10,49 & 33,20 & $21,69 \pm 6,5$ \\
\hline
\end{tabular}

${ }^{*} \mathrm{mg} / \mathrm{dl}$.

riores a los registrados en alpacas y llamas adultas (Oevermann et al., 2004). Esta hiperglucemia observada puede ser atribuible a la falta de ejercicio, es decir en el gasto energético de estos (Guyton y Hall, 2001), dado que la vicuña es un animal aclimatado a vivir en alturas, y corre grandes distancias, por tanto durante el ejercicio prolongado el principal sustrato energético es la glucosa, mientras que al final son la grasas (García et al., 1995) no dándose lo explicado en las condiciones de cautiverio. Dado que el metabolismo de la glucosa en camélidos es aún desconocido, los niveles elevados de glucosa podrían atribuirse a una resistencia moderada a la insulina (Cebra et al., 2001). Los niveles de colesterol encontrados, son superiores a los registrados en equino, bovino, cerdo, gato y perro (Kraft, 1998) y se encuentran por encima de lo establecido para vicuñas en reposo (Garnica et al., 2003) igualmente superiores para lo hallado en llamas, camellos y alpacas (Purdy, 2004). Reflejando, una elevación en la concentración de colesterol, los cambios que se producen en la alimentación.

Ilamas and alpacas. Am. J. Vet. Res., 62: 682686.

Cunningham, J. 1999. Fisiología veterinaria. Edit. Mc Graw-Hill Interamericana. México.

Kraft, H. 1998. Métodos de laboratorio clínico en medicina veterinaria de mamíferos domésticos. 


\section{PERFIL SANGUINEO DE LA VICUÑA (VICUGNA VICUGNA) EN CAUTIVERIO}

Edit. Acribia. Zaragoza. España.

Fowler, M.E. 1998. Medicine and surgery of South American camelids. $2^{\text {nd }}$ ed. lowa State University Press. Ames. pp. 549

García, A., Castejón, F., Cruz, L. de la, Gonzáles, J., Murillo, M. y Salido, G. 1995. Fisiología veterinaria. Edit. Mc Graw-Hill Interamericana. Madrid. España.

Garnica, J., Arocutipa, M. y Bravo, W. 2003. Componentes bioquímicos de la sangre de vicuñas en el altiplano peruano. En: Resúmenes III Congreso Mundial sobre Camélidos. Potosí. Bolivia.

Guyton, A. y Hall, J. 2001. Tratado de fisiología médica. Edit. Mc Graw-Hill Interamericana. México.

Hofmann, R.K. Otte, K., Ponce, C.F. y Rios, M. 1983. El manejo de la vicuña silvestre. Tomo III. Sociedad alemana de cooperación técnica (GTZ).
Lichtenstein, G. Oribe, F., Grieg-Gran, M. y Mazzucchelli, S. 2002. Manejo comunitario de vicuñas en Perú. Estudio de caso del manejo comunitario de vida silvestre. PIE Series $\mathrm{N}^{\circ} 2$.

Oevermann, A., Pfyffer, G., Zanolari, P., Meylan, M. and Robert, N. 2004. Generalized tuberculosis in llamas (Lama glama) due to Mycobacterium microti. J. Clin. Microbiol., 4: 1818-1821.

Pérez, C. 2001. Técnicas estadísticas con SPSS. Prentice Hall. España.

Purdy, S. 2004. Normal alpaca and llama blood values. In: http://www.purdyvet.com.

Siguas, O. 2005. Perfil sanguíneo en vicuñas el CICS Lachocc. En: Resúmenes XXVIII Reunión Científica Anual de la Asociación Peruana de Producción Animal (APPA). Iquitos.

Wiener, 2000. Protocolos para determinación de glucosa, bilirrubina, triglicéridos, colesterol y transaminasas en suero sanguíneo. Wiener. Lab. Rosario. Argentina. 